\title{
Factors affecting the survival probability of becoming a centenarian for those aged 70 , based on the human mortality database: income, health expenditure, telephone, and sanitation
}

Jong In Kim ${ }^{1 *}$ and Gukbin Kim²

\begin{abstract}
Background: What are the factors that affect the survival probability of becoming a centenarian for those aged 70 ? Do the factors include income, health expenditure, the use of mobile telephones, or sanitation? The survival probability of becoming a centenarian (SPBC) is defined as an estimate of the production of centenarians by a population. The SPBC (70) is the survival probability of becoming a centenarian for those aged 70. This study estimates the associations between the SPBC (70), and the gross national income, health expenditure, telecommunications, and sanitation facilities in 32 countries.
\end{abstract}

Methods: The socioeconomic indicators for this study were obtained from the database of the United Nations Development Programme. In addition, the data for the analysis of centenarians in 32 countries were obtained from the Human Mortality Database, which is maintained by the Department of Demography at the University of California, Berkeley, USA, and the Max Planck Institute for Demographic Research in Rostock, Germany. Associations between socioeconomic indicators and SPBC (70) were assessed using Pearson's correlation coefficients and multiple regression models.

Results: Significant positive correlations were found between the SPBC (70), and the socioeconomic factors of gross national income (GNI), public expenditure on health as a percentage of gross domestic product (PEHGDP), fixed and mobile telephone subscribers (FMTS) as the standard of living, and improved sanitation facilities (ISF). Overall, the SPBC (70) of female and male predictors were used, in order to form a model production of centenarians, with higher GNI and PEHGDP, as well as higher FMTS and ISF as the socioeconomic factors $\left(R^{2}=0.422, P<0.001\right)$.

Conclusions: The socioeconomic level in all 32 countries appears to have an important latent effect on the production of centenarians in both females and males. This study has identified the following four important aspects of socioeconomic indicators in the survival probability of becoming a centenarian for those aged 70: higher overall economic development level, public expenditure on health, mobile telephone subscribers as the standard of living, and the use of improved sanitation facilities for healthy aging. Thus, the socioeconomic level seems to affect an important on the survival probability of becoming a centenarian.

Keywords: Centenarians, Survival probability, Human mortality database, Data quality, Gross national income, Sanitation facilities, Health expenditure, Longevity index, Healthy aging

\footnotetext{
* Correspondence: kji122@wku.ac.kr

${ }^{1}$ Division of Health and Welfare, Wonkwang University, Iksan 570-749,

Republic of Korea

Full list of author information is available at the end of the article
} 


\section{Background}

What are the factors that affect the survival probability of becoming a centenarian for those aged 70? Do the factors include income, health expenditure, the use of mobile telephones, or sanitation?

In many countries, the survival probability of becoming a centenarian $(\mathrm{SPBC})$ has been increasing over the past several decades, particularly among women. While the survival of centenarians is improving, at least in some countries, it is not possible to determine whether the natural life span has increased overall [1]. However, the SPBC may have been affected by the above socioeconomic indicators. This retrospective analysis of the socioeconomic factors, which contribute to the SPBC, may help identify the factors associated with healthy aging.

Today, the population of centenarians is steadily increasing globally [2]. Over the past half-century, the number of centenarians has dramatically increased [3]. The determinants regarding the increase in the number of centenarians include the cohort size at selected ages, along with the probability of survival at selected ages [4]. Namely, the number of centenarians reflects an estimate of the production of centenarians at selected ages, which is the survival probability of becoming a centenarian within a population. Therefore, the SPBC is defined as an estimate of the production of centenarians by a population. Further, the SPBC (70) is the survival probability of becoming a centenarian for those who are aged 70.

Historically, Sachuk [5] first suggested the longevity index in 1970, as the proportion between the number of centenarians and the total population [6]. This value depends on the population structure [7]. The SPBC (70), as an indicator of healthy aging, is based on an unchanged age-specific fertility, as well as on the absence of migration in populations. However, in this study, the SPBC (70), as the centenarian rate has nothing to do with fertility, because the study cohorts have already reached the age of 70 . Meanwhile, the probability of survival as the number of centenarians, suggested by Robine and Caselli [4], used to be an indicator of healthy aging in response to the imperfection of the longevity index, thereby resulting in a longevity index that is used in certain countries [4-6,8,9].

Healthy aging is an important aspect for the health of centenarians. It requires older people to have access to appropriate improved sanitation facilities; moreover, public expenditure on health and a sense of satisfaction with their level of income, as well as using mobile phones as the standard of living, are essential as well. This paper therefore seeks to determine the association between such socioeconomic indicators, and the SPBC (70).

In particular, although knowledge of the determinants of healthy aging is limited, healthy aging of centenarians is a multifactorial quantitative trait that is influenced by biological, environmental, and psychosocial factors [10].
Among all these elements, socioeconomic factors, as modifiable risk factors, have been researched in several studies. In brief, studies have shown that environmental health factors, such as drinking water and sanitation facilities, can predict mortality in incidences of cancer and diarrhea $[11,12]$. However, it is uncertain as to whether these associations are applicable to the SPBC (70), as the production of centenarians. The results concerning the association between the use of telephones, the use of mobile phones, and the improvement of health outcomes, have also been studied $[13,14]$. However, it is uncertain as to whether these associations are applicable to the SPBC (70) as the number of centenarians. Finally, previous reports have supported the hypothesis that the associations between national economic indicators and relative fitness among the older population are positive [15]; however, these relations have not been confirmed in other studies of centenarians [16]. Although the socioeconomic indicators, as modifiable risk factors, have been studied in several studies, it is uncertain as to whether these associations are applicable to the production of centenarians.

Therefore, this study has examined the associations of independent socioeconomic indicators with SPBC (70), as the number of centenarians. Further, this study estimates the influence that correlates between the SPBC (70) and gross national income, health expenditure, the use of mobile telephones, and sanitation facilities, as the socioeconomic indicators in 32 countries. Overall, this study aims to estimate the association between the SPBC (70) and socioeconomic factors, by using Pearson's correlation coefficients and multiple regression models.

\section{Methods}

\section{Estimation of the SPBC (70)}

This study's objective is to identify the differences in the socioeconomic indicators related to the SPBC (70) within 32 countries. The SPBC (70) has the advantage of controlling other potential confounders, such as infant mortality, which affect the number of centenarians, and overcoming the problem of migration inherent in the change of nationality. The SPBC (70) is the number of survivors who are aged 100 at a given date, divided by the size of the corresponding cohort at a given age $[4,9]$. This study utilized the Human Mortality Database (HMD) of centenarians from 32 countries for calculation [17]. The HMD classifies these countries into several categories by the quality of agereporting data at very old ages. Therefore, we have used data from the human mortality database, where most countries have relatively good data quality to perform their analysis. In order to become a centenarian, it takes a period of over 30 years for those who are aged 70, which is the years of data used in all countries from 1980 to 2010. As a result, with regard to the last thirty years, the SPBC (70) reflects the number of those aged 100 in the 
year 2010, divided by the size of the corresponding cohort at the age of 70 in 1980 [SPBC (70)= (The number of those aged 100 in 2010/The number of those aged 70 years in 1980)* 10000]. This calculation implies that it is the number of people aged 70 in 1980 who reached 100 in 2010 , as a retrospective study, as well as an estimate of the production of centenarians (see Additional file 1). The SPBC (70) comprises cohorts who were born in 1910. The meaning of SPBC (70) is to live until those aged 70 years become centenarians. More specifically, life expectancy is the expected number of years of life remaining at a given age. However, the SPBC (70), which is an indicator for assessing the production of centenarians, or the number of centenarians by a population, reflects the longevity of a population in 32 countries, or the survival probability of becoming centenarians for those aged 70 (Figure 1).

\section{The framework of the factors that affect survival}

The proposed framework of this study depicts the socioeconomic factors for SPBC (70), as the number of survivors who are centenarians (Figure 1). In fact, centenarians have been an influence on the socioeconomic factors for this period.

Healthy aging of centenarians is a multifactorial quantitative trait, which is influenced by biological, psychosocial, and environmental factors $[10,18]$. Healthy aging in centenarians indicates the physical activity of living for at least a hundred years with the absence of diseases, alongside being characterized by the preservation of functional capacity and social well being, as exemplified through active life in society [9,19-21]. In particular, the SPBC (70), as the production of centenarians, may be affected under the control of a social environment and a hereditary factor. However, the SPBC (70) of this study excludes the effect by hereditary factors. The reason as to why the individual-level factors are omitted in the study provides the notion that individual characteristics are closely linked to mortality, because that ceteris paribus assumption in individual characteristics, which correlates to SPBC (70), only has to consider the socioeconomic level from a macroscopic viewpoint.

Although the biological factors could be directly impacted by physical factors, they are indirectly affected by environmental health factors. These factors could be found in drinking water and sanitation facilities [11,12]. Thus, as a higher proportion of the population uses improved sanitation facilities (ISF), there will be a greater promotion of health as a preventive measure against waterborne infections $[22,23]$ and sanitary-related gastroenteric diseases, such as diarrhea [24], among the older population.

On the other hand, the association between the use of telephones and improved health has also been studied $[13,14]$. The hypothesis of this study is that the associations between fixed and mobile telephone subscribers (FMTS), as the standard of living of socioeconomic factors, and the
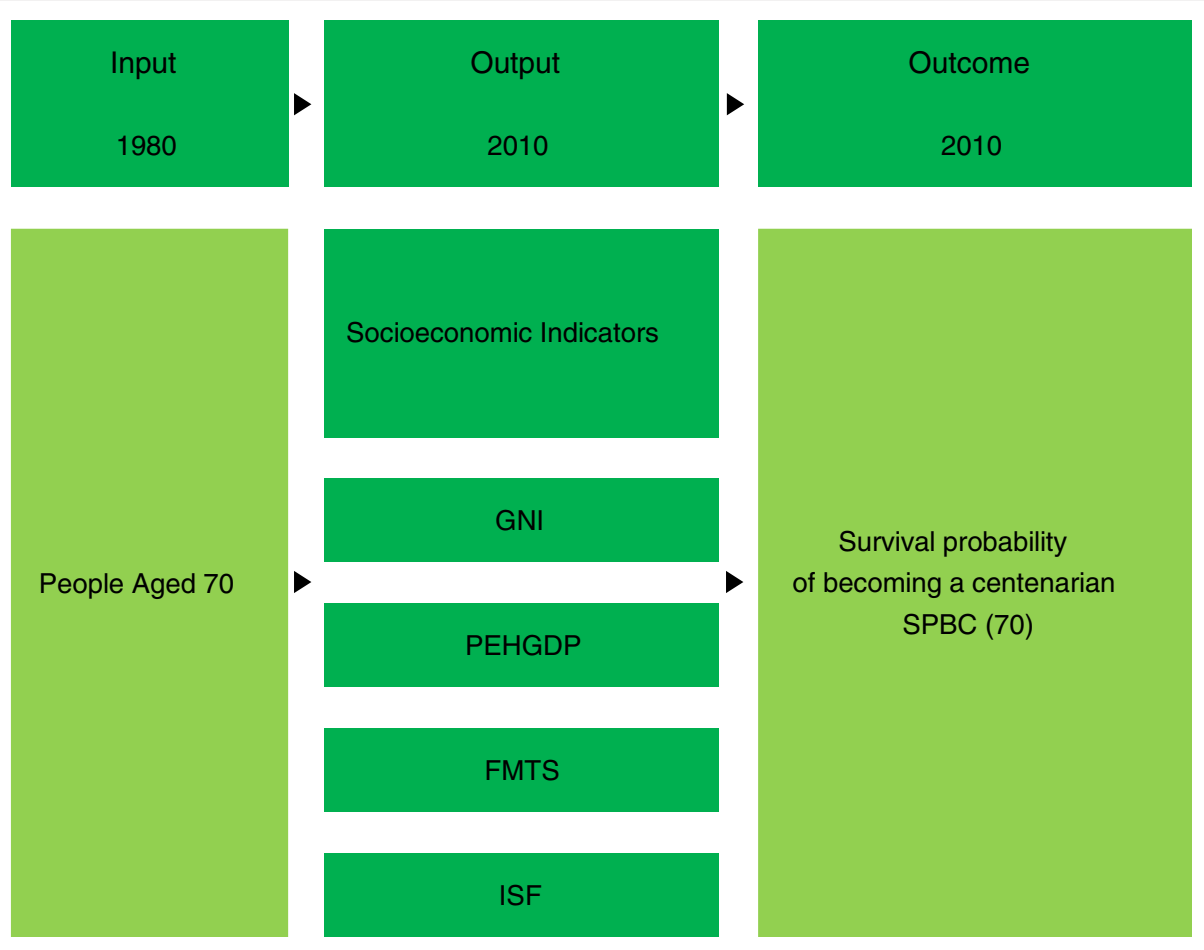

Figure 1 Description of theoretical framework. 
SPBC (70) may differ among centenarians in developed countries, or be comparable with those in undeveloped countries.

Finally, although the associations between health expenditures and their relationship with the number of centenarians in 32 OECD countries [9], along with the national income and healthcare spending in their relationship with mortality among the older population, are correlated [15], it is uncertain as to whether these associations are applicable to the number of centenarians with social well-being, such as public expenditure on health as a percentage of gross domestic product (PEHGDP) and gross national income (GNI), among the study of 32 countries.

Hence the hypothesis, that the associations between SPBC (70) as outcomes, and sanitation facilities (ISF), use of mobile telephones (FMTS), health expenditure (PEHGDP), and national income (GNI) as outputs, can predict the survival probability of becoming centenarians. These factors could be explained by healthy aging, which affects the survival probability of becoming centenarians; the SPBC (70) deals with the survival probability of becoming 100 years in 2010, for those aged 70 in 1980 (Figure 1).

\section{Deriving the hypothesis, and setting the models}

In order to examine the association between the SPBC (70) and the socioeconomic factors of healthy aging, we need to set a study model for each variable. This model was used to estimate the SPBC (70), in terms of the socioeconomic indicators. The models depict the framework proposed herein of the socioeconomic factors of healthy aging, according to the variables selected. The three models yielded the following results. The SPBC (70), as predictors, was used to form a model combination, as the nub of the economic factors GNI and PEHGDP, with FMTS and ISF as social factors. These variables are reflective of the health expenditure and sanitation factors, as well as the economic development level and telecom attainment indicators. Thus, model 1 is the SPBC (70) of females and males, model 2 is the SPBC (70) of males, and model 3 is the SPBC (70) of females. All of the models were used to form a model with GNI and PEHGDP, and FMTS and ISF factors for the production of centenarians, which may differ among the elderly in all 32 countries. Therefore, from this model, we derived a hypothesis stating that increases in GNI and PEHGDP, which are earmarks of income, as well as increases in FMTS and ISF, will lead to a corresponding increase in the SPBC (70) in all 32 countries. In contrast, decreases in GNI and PEHGDP, as well as decreases in FMTS and ISF, will result in a corresponding decrease in the SPBC (70).

Data collection and estimate of socioeconomic indicators Ethics approval for the study was obtained from the Institutional Review Board Wonkwang University (WKIRB-
201409-SB-057). The data for the analysis of the centenarians were obtained from the Human Mortality Database (HMD), which is maintained by the Department of Demography at the University of California, Berkeley, USA, and the Max Planck Institute for Demographic Research in Rostock, Germany [17]. The countries and overseas island dependencies were selected according to the classification system applied by the United Nations.

For the SPBC (70) analyses, this study excluded countries for which information on the number of centenarians was insufficient. A total of 32 countries were selected. The socioeconomic factors for this study were obtained from the data by country in the United Nations Development Programme [25], and a dataset in the United Nations database [26]. Because the SPBC (70) focuses on the cohorts for over a 30-year period, the socioeconomic factors during the period would have largely changed. Therefore, it is proper to examine the association between the SPBC (70) and socioeconomic indicators. There are at least time series data for using a telephone, economic development level, health expenditure, and sanitation, which will make the results more robust. Further, there are two comparability issues for the present study. One is comparability across countries, whereas the other is comparability across periods from 1980 to 2010, which the socioeconomic factors have considered. Because the SPBC (70) is a type of dynamic and outcome indicator (Figure 1) that represents the improvement of mortality that is closely related to the country-level socioeconomic development, we need to employ the equivalent indicator.

Therefore, the SPBC has been used as the mean rate of change index (MRCI), i.e. the growth rate or rate of decline, in order to measure the change of socioeconomic indicators during the past thirty years. The MRCI was used to supplement faults in such information, because some countries experienced greater progress in 1980 to 2010, whereas some did not. The MRCI can be maintained not only by the present value of the indicator, but also can consider the change rate in 1980 to 2010 . The MRCI is the change in the value of a quantity divided by the elapsed time $[27,28]$. Further, the socioeconomic indicators in this study reflect the MRCI, the sum of the change in the value of quantity indications from 1980 to 2010, divided by the number (N) of elapsed years [The MRCI= (The present value at that time of indicators in $1980+$ The value of change indicators of the growth rate or rate of decline in 2010)/N], as an estimate of the time series data of socioeconomic development indicators. However, this study excluded those indicators for which information on socioeconomic development indicators was insufficient in the time series data.

The following factors were used: (1) GNI (Gross National Income) per capita (constant 2005 international \$) [25]: aggregate income of an economy generated by its production and ownership of factors of production, less the incomes 
paid for the use of factors of production owned by the rest of the world, converted to international dollars using purchasing power parity (PPP) rates, divided by midyear population, from 1990 to 2010; (2) FMTS (Fixed and mobile telephone subscribers per 100 people) [25]: sum of telephone lines and mobile subscribers, expressed per 100 people, from 1980 to 1990, and from 1980 to 2000; (3) PEHGDP (Expenditure on health, public\% of GDP) [25]: current and capital spending from government central and local budgets, external borrowings and grants, including donations from international agencies and nongovernmental organizations, and social or compulsory health insurance funds, expressed as a percentage of GDP, from 2000 to 2010; and (4) ISF (Improved sanitation facilities, urban) [26]: access to improved sanitation facilities refers to the percentage of the population using improved sanitation facilities. The improved sanitation facilities include flush/pour flush (to piped sewer system, septic tank, pit latrine), ventilated improved pit (VIP) latrine, pit latrine with slab, and composting toilet from 2005 to 2010.

\section{Descriptive statistics}

Table 1 presents the descriptive statistics for this range of SPBC (70), along with the socioeconomic factors. The SPBC (70) MF of the 32 countries ranged from 19 in the Ukraine, to 250 in Japan. The SPBC (70) M of the 32 countries ranged from 9 in the Ukraine, to 83 in Japan. The SPBC (70) F of the 32 countries ranged from 24 in the Ukraine, to 381 in Japan. The mean ISF ranged from $75 \%$ in Russia, to $100 \%$ in Japan, Canada, Switzerland, France, Australia, and the United Kingdom, with a mean of $97.85 \%$. The mean FMTS ranged from 7.05 in Poland, to 65.85 in Sweden, with a mean of 30.76. The mean PEHGDP ranged from 3.2 in Russia, to 8.65 in France, with a mean of 6.16. Lastly, GNI was the lowest in the

\section{Table 1 Descriptive statistics of variable}

\begin{tabular}{cccccc}
\hline Variable & N & Mean & StDev a & Minimum & Maximum \\
\hline SPBC (70) MF & 32 & 80.28 & 51.36 & 19 & 250 \\
SPBC (70) M & 32 & 32.41 & 19.05 & 9 & 83 \\
SPBC (70) F & 32 & 116.7 & 79.6 & 24 & 381 \\
GNI & 32 & 23889 & 9627 & 7095 & 44679 \\
PEHGDP & 32 & 6.16 & 1.52 & 3.2 & 8.65 \\
FMTS & 32 & 30.76 & 16.03 & 7.05 & 65.85 \\
ISF & 32 & 97.85 & 5.51 & 75.02 & 100 \\
\hline
\end{tabular}

a: Standard deviation.

SPBC (70): Survival probability of becoming a centenarian for those aged 70 (per 10,000).

MF: Females and Males, M: Males, F: Females.

GNI: Gross National Income per capita (constant 2005 international \$) (1990-2010). PEHGDP: Public expenditure on health as a percentage of GDP (\% of GDP) (2000-2010).

FMTS: Fixed and mobile telephone subscribers (per 100 people) (1980-1990). ISF: Proportion of the population using improved sanitation facilities (\%), urban (2005-2010).
Ukraine (GNI, \$7,095), and was the highest in Luxembourg (GNI, \$44,679), with a mean of $\$ 23,889$ across all 32 countries.

\section{Results}

The impact and prediction variables of SPBC (70)

In order to investigate the direct relationships between the socioeconomic variables involved in healthy aging and SPBC (70) in the 32 countries studied, this paper conducted a multiple regression analysis. Table 2 presents an analysis of the socioeconomic factors related to the SPBC (70) in all 32 countries. The fitted line plots of country characteristics against the SPBC (70) are presented, in order to indicate the strength of the associations between these socioeconomic factors and the production of centenarians. Significant positive correlation coefficients were found between the SPBC (70), and the entire socioeconomic factors of GNI $(\mathrm{r}=0.555, \mathrm{p}<0.001)$, PEHGDP $(\mathrm{r}=0.583, \mathrm{p}<0.001)$, ISF $(r=0.382, p<0.0311)$ and FMTS $(r=0.611, p<0.001)$ (Table 2). A log scale was used for all explanatory variables (see Figures 2, 3, 4 and 5). The regression analysis of the socioeconomic factors discovered the prediction of univariate variables for SPBC (70) in 32 countries (Table 3), which are the strongest predictors among the three regression models (Tables 4 and 5). The SPBC (70) of female predictors was used to form a model regarding the production of centenarians, including higher GNI, FMTS, PEHGDP, and ISF factors $\left(\mathrm{R}^{2}=0.439, \mathrm{P}<0.003\right)$; however, SPBC (70) of males predictors was also used to form a model with higher GNI, FMTS, PEHGDP, and

Table 2 Correlations of the indications with SPBC (70)

\begin{tabular}{cccc}
\hline P-Value & & Correlations coefficient & P-Value \\
\hline SPBC (70) MF & GNI & 0.555 & 0.0001 \\
& PEHGDP & 0.583 & 0.0001 \\
& FMTS & 0.611 & 0.0001 \\
& ISF & 0.382 & 0.0311 \\
SPBC (70) M & GNI & 0.421 & 0.0017 \\
& PEHGDP & 0.457 & 0.0081 \\
& FMTS & 0.521 & 0.0021 \\
& ISF & 0.351 & 0.0491 \\
SPBC (70) M & GNI & 0.568 & 0.0001 \\
& PEHGDP & 0.594 & 0.0001 \\
& FMTS & 0.623 & 0.0001 \\
& ISF & 0.391 & 0.0281
\end{tabular}

SPBC (70): Survival probability of becoming a centenarian for those aged 70 (per 10,000).

MF: Females and Males, M: Males, F: Females.

GNI: Gross National Income per capita (constant 2005 international \$) (1990-2010). PEHGDP: Public expenditure on health as a percentage of GDP (\% of GDP) (2000-2010).

FMTS: Fixed and mobile telephone subscribers (per 100 people) (1980-1990). ISF: Proportion of the population using improved sanitation facilities (\%), urban (2005-2010). 

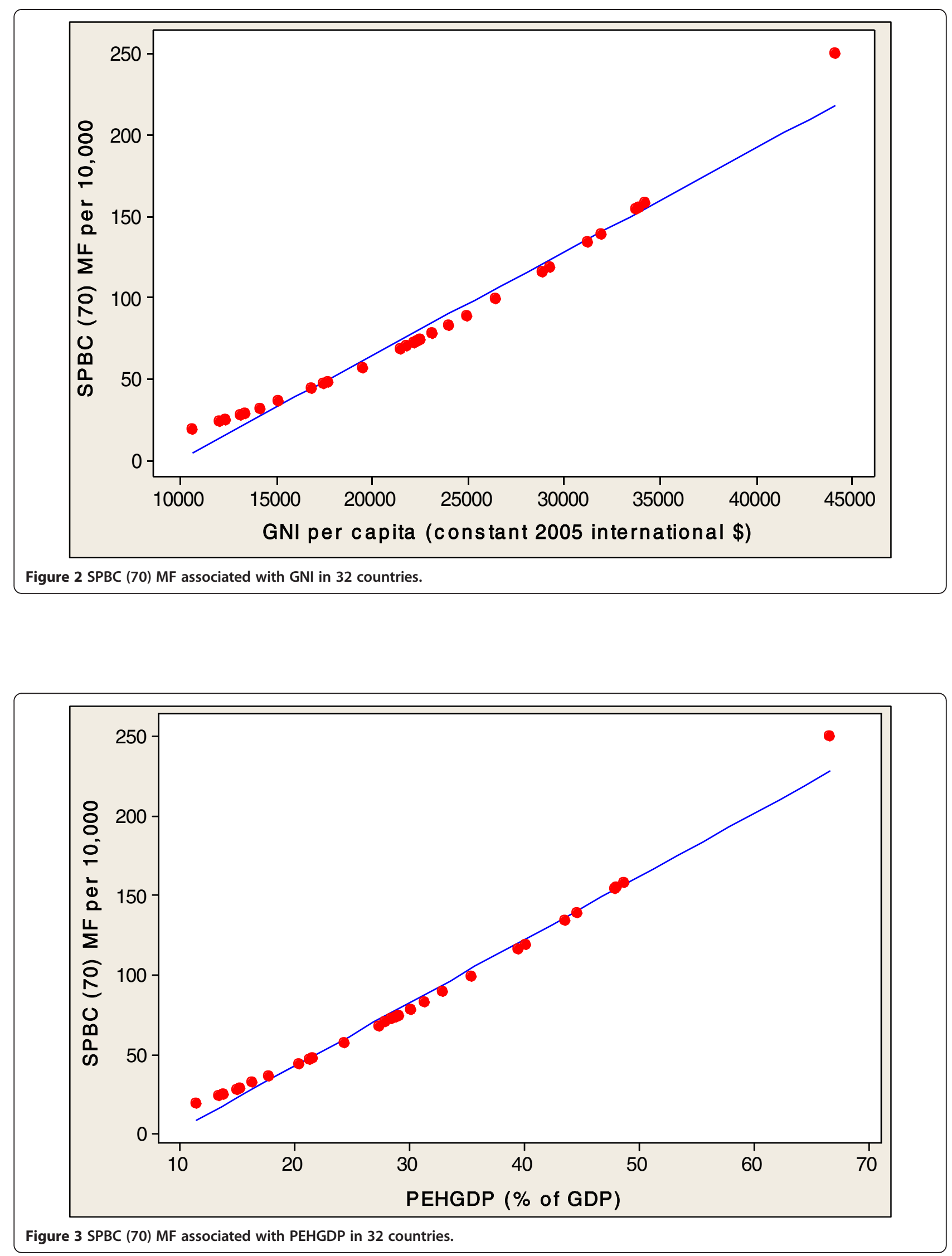

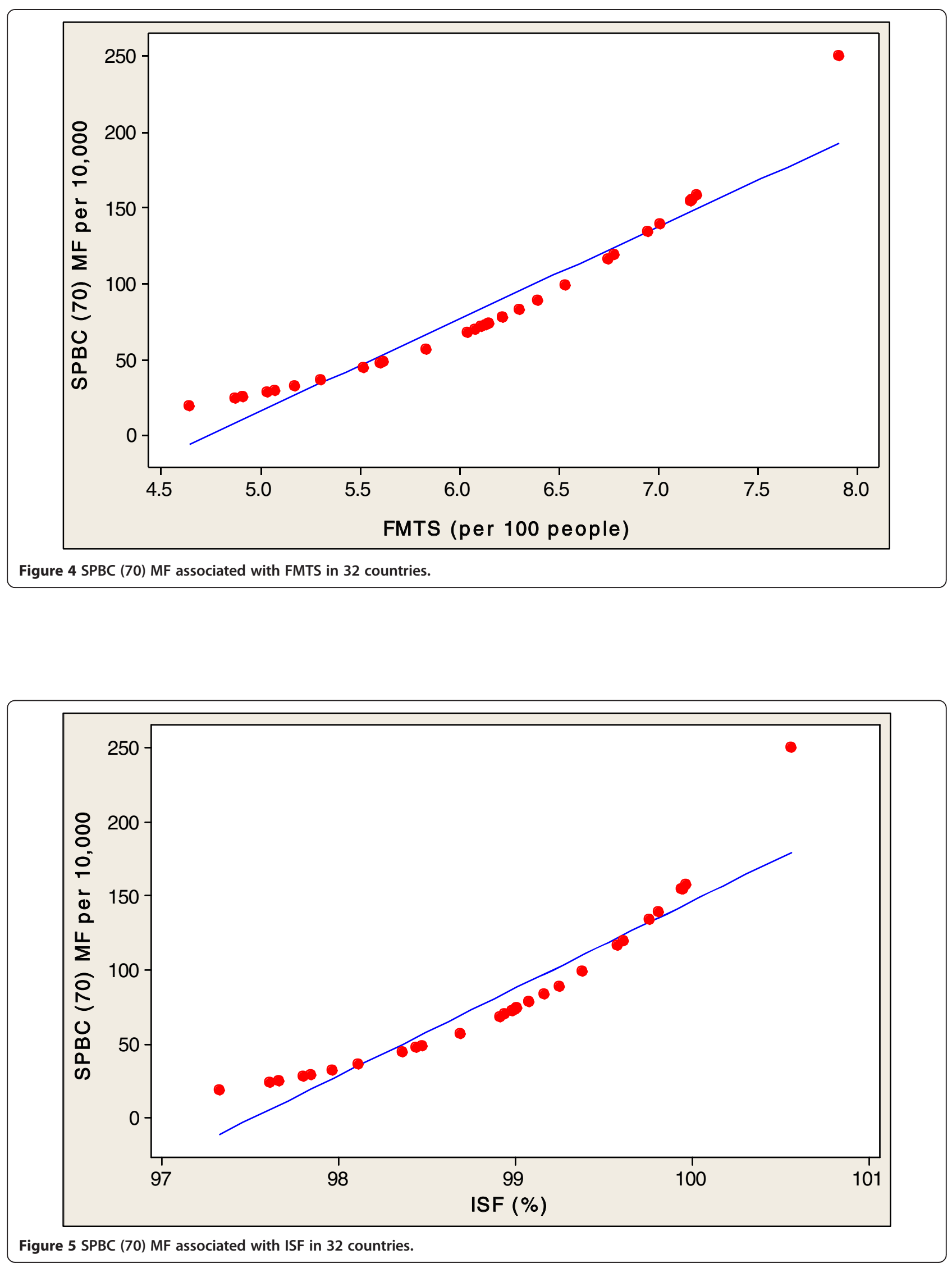
Table 3 Univariate variables for the SPBC (70)

\begin{tabular}{lccccc}
\hline & Variable & Coefficient & T-Value & P-Value & $\mathbf{R}^{\mathbf{2}}$ \\
\hline SPBC (70) MF & GNI & 0.002 & 3.65 & 0.001 & 0.308 \\
& PEHGDP & 19.87 & 3.93 & 0.001 & 0.341 \\
& FMTS & 1.966 & 3.93 & 0.001 & 0.371 \\
& ISF & 3.583 & 2.26 & 0.003 & 0.146 \\
SPBC (70) MF & GNI & 0.008 & 2.54 & 0.001 & 0.177 \\
& PEHGDP & 5.751 & 2.82 & 0.008 & 0.209 \\
& FMTS & 0.619 & 3.35 & 0.002 & 0.272 \\
& ISF & 1.212 & 2.04 & 0.049 & 0.122 \\
SPBC (70) MF & GNI & 0.004 & 3.78 & 0.001 & 0.322 \\
& PEHGDP & 31.19 & 4.05 & 0.001 & 0.353 \\
& FMTS & 3.089 & 4.36 & 0.001 & 0.388 \\
& ISF & 5.635 & 2.32 & 0.028 & 0.152 \\
\hline
\end{tabular}

SPBC (70): Survival probability of becoming a centenarian for those aged 70 (per 10,000).

MF: Females and Males, M: Males, F: Females.

GNI: Gross National Income per capita (constant 2005 international \$) (1990-2010). PEHGDP: Public expenditure on health as a percentage of GDP (\% of GDP) (2000-2010).

FMTS: Fixed and mobile telephone subscribers (per 100 people) (1980-1990). ISF: Proportion of the population using improved sanitation facilities (\%), urban (2005-2010).

Table 4 Multiple regression models for predicting SPBC (70)

\begin{tabular}{lccccc}
\hline & Variable & Coefficient & T-Value & P-Value & $\mathbf{R}^{\mathbf{2}}$ \\
\hline SPBC (70) MF & GNI & 0.001 & 1.28 & 0.001 & 0.376 \\
& PEHGDP & 13.01 & 1.78 & & \\
& FMTS & 1.763 & 3.93 & 0.001 & 0.391 \\
& ISF & 1.385 & 0.92 & & \\
& PEHGDP & 10.47 & 1.56 & 0.001 & 0.421 \\
& FMTS & 1.277 & 2.01 & & \\
SPBC (70) MF & GNI & 0.003 & 0.77 & 0.005 & 0.225 \\
& PEHGDP & 4.052 & 1.35 & & \\
& FMTS & 0.541 & 2.63 & 0.007 & 0.291 \\
& ISF & 0.536 & 0.89 & & \\
& PEHGDP & 2.311 & 0.84 & 0.007 & 0.289 \\
& FMTS & 0.467 & 1.81 & & \\
SPBC (70) MF & GNI & 0.002 & 1.35 & 0.001 & 0.392 \\
& PEHGDP & 20.23 & 1.82 & & \\
& FMTS & 2.769 & 3.52 & 0.001 & 0.406 \\
& ISF & 2.181 & 0.95 & & \\
& PEHGDP & 16.41 & 1.61 & 0.001 & 0.438 \\
& FMTS & 2.011 & 2.09 & & \\
\hline
\end{tabular}

SPBC (70): Survival probability of becoming a centenarian for those aged 70 (per 10,000$)$.

MF: Females and Males, M: Males, F: Females.

GNI: Gross National Income per capita (constant 2005 international \$) (1990-2010). PEHGDP: Public expenditure on health as a percentage of GDP (\% of GDP) (2000-2010)

FMTS: Fixed and mobile telephone subscribers (per 100 people) (1980-1990). ISF: Proportion of the population using improved sanitation facilities (\%), urban (2005-2010).
Table 5 Multiple regression models for predicting SPBC (70)

Model 1

(1) $Y_{1}=-50.959+2.450 E-5 X_{1}+9.692 X_{2}+1.268 X_{3}+0.327 X_{4}+E n$

$R^{2}=0.422, F-$ Value $=4.933, P=0.004$

Model 2

(2) $Y_{2}=-30.612+0.00001 X_{1}+1.984 X_{2}+0.586 X_{3}+0.412 X_{4}+E n$

$$
R^{2}=0.303, \text { F-Value }=2.939, P=0.039
$$

Model 3

(3) $Y_{3}=-89.981+0.00001 X_{1}+15.034 X_{2}+1.974 X_{3}+0.512 X_{4}+E n$

$$
R^{2}=0.439, \text { F-Value }=5.278, P=0.0031
$$

Model 1, 2, 3:

: Economic level (+) Health expenditure (+) Using fixed and mobile telephone $(+)$ Sanitation.

$Y_{1}=\operatorname{SPBC}(70) \mathrm{MF}$.

$\mathrm{Y}_{2}=$ SPBC (70) M.

$\mathrm{Y}_{3}=\operatorname{SPBC}(70) \mathrm{F}$.

$\mathrm{X}_{1}=\mathrm{GNI}$.

$X_{2}=$ PEHGDP.

$X_{3}=$ FMTS

$\mathrm{X}_{4}=\mathrm{ISF}$.

SPBC (70): Survival probability of becoming a centenarian for those aged 70 (per 10,000).

MF: Females and Males, M: Males, F: Females.

GNI: Gross National Income per capita (constant 2005 international \$) (1990-2010). PEHGDP: Public expenditure on health as a percentage of GDP (\% of GDP) (2000-2010).

FMTS: Fixed and mobile telephone subscribers (per 100 people) (1980-1990). ISF: Proportion of the population using improved sanitation facilities (\%), urban (2005-2010).

ISF factors $\left(R^{2}=0.303, P<0.039\right)$. Finally, the SPBC $(70)$ of female and male predictors were used to form a model production of centenarians with higher GNI and FMTS, as well as higher PEHGDP and ISF as socioeconomic factors $\left(\mathrm{R}^{2}=0.422, \mathrm{P}<0.004\right)$ (see Table 5).

\section{Discussion}

This study investigated the socioeconomic factors associated with the SPBC (70). The present SPBC (70) MF, which is based on a study of centenarians and factors from the national censuses of 32 countries examined in this study, indicated an average of 80.28 centenarians per 10,000 . In this study, the SPBC (70) was used to help create a model identifying the socioeconomic factors on the survival probability of becoming a centenarian for those aged 70 .

First, the social factor of ISF (2005-2010), which indirectly reflects the environmental health [11,12,22-24] that is necessary for the survival probability of becoming centenarians, was included in all Models 1, 2 and 3 of females and males, which were found to be a significant factor for the production of centenarians. In the current study, the ISF in Russia (ISF $=75 \%$ ) was the lowest among all 32 countries; whereas, those of Japan, Canada, Switzerland and United Kingdom (ISF $=100 \%)$ were the highest. The ISF is likely to be a major contributing factor to a high SPBC (70) in certain countries. The mortality rate stemming from the ISF is also a well-known public health 
concern. This implies that older people who are vulnerable to the risk of ISF might not have the same life expectancy as centenarians. In Russia, the occurrence of typhus epidemic, particularly in circumstances where people are interned under poor hygienic conditions, should be regarded as a barometer for the general social situation. If these indicators are ignored, the consequences could be disastrous [29]. These examples should highlight the fact that immediate intervention to combat the louse epidemic is essential, in order to eradicate emerging typhus among the general population of Russia [29]. This notion means ensuring that the importance of sanitation for infectious diseases is recognised. On the other hand, Russia has the lowest ISF for the production of centenarians, because both of these variables are reflective of a lack of any government investment in health and hygiene facilities infrastructure. The production of centenarians in this study has been indirectly affected by the environment health factors, namely the ISF. Therefore, among the centenarians, the higher the ISF, the greater is the promotion of health as a preventive measure against infectious diseases [22,23] and sanitary facilities [24]. Simultaneously, using the ISF might help maintain the requisite environmental health for the production of centenarians. Therefore, the predictors' correlations between the SPBC (70) and ISF are strongly positive, which may well indicate that the ISF is an important independent contributor to the survival probability of becoming centenarians.

Second, the social factor of FMTS (1980-2000), which indirectly reflects the standard of living, can contribute to the health aspect, by accessing health-related information $[13,14]$, as well as the high-levels in the quality of life [9]; these were included in all Models 1, 2, and 3 of females and males. Increases in FMTS led to an increase in SPBC (70) values, suggesting that they are significant contributory factors to the healthy aging and production of centenarians. In the current study, the FMTS score in Poland (FMTS=7) was the lowest among all 32 countries; whereas, that of Sweden (ISF=66) was the highest. The FMTS is likely to be a major contributing factor to a higher SPBC (70) in 32 countries. Therefore, the FMTS was included in all Models 1, 2 and 3 of females and males, which indirectly reflect the health factors for both social well-being and standard of living, which are necessary for healthy aging and the production of centenarians; further, they were found to be significant factors of healthy aging (Tables 4 and 5). This result implies that the current study has high correlations between FMTS and the survival probability of becoming centenarians, because both of these variables are reflective of the government's investment in telecommunications infrastructure in health, highlevel in the quality of life, and individual income of citizens in developed countries [9]. On the other hand, if an individual's mental health improves by periodic telephone counseling, then human relationships, which maintain social relationships with family and friends in the oldest-old, might have beneficial effects on mental health [30,31]. Therefore, periodic telephone counseling appears to have an important latent effect on mortality into late life [31]. Moreover, telemedicine and conventional health services are complementary for enhancing the health status in an aging society [32]. The FMTS is an important independent contributor to the survival probability of becoming centenarians for those aged 70 (Tables 4 and 5).

Finally, economic factors of PEHGDP (2000-2010) and GNI (1990-2010), which indirectly reflect the standard of living and income level $[9,15]$ that are necessary for the survival probability of becoming centenarians, were included in all Models 1, 2 and 3 of females and males; moreover, they were found to be a significant factor in the production of centenarians. In the current study, the PEHGDP in Russia (PEHGDP=3.2) and GNI in the Ukraine $(\mathrm{GNI}=7095)$ were the lowest among all 32 countries; whereas, the PEHGDP in France (PEHGDP=8.65) and GNI in Luxembourg $(\mathrm{GNI}=44679)$ were the highest. The PEHGDP and GNI are likely to be major contributing factors to a high SPBC (70) in certain countries. Increases in the GNI and PEHGDP led to an increase in the SPBC (70), thereby suggesting that the PEHGDP and GNI are significant factors of the production of centenarians in all models of females and males. Although the relationship of economic indicators with health is unclear, lower income has been associated with morbidity [15]. In fact, death rates exceeded emergency thresholds at 4 sites during epidemics of Plasmodium falciparum malaria in Burundi [33]. However, in higher-income countries, the prevalence of frailty is lower, and people live longer [15]. Therefore, Models 1, 2, and 3 of females and males predictors' correlations between the SPBC (70) and the PEHGDP and GNI are all strongly positive, which may well indicate that the PEHGDP and GNI are important independent contributors to the production of centenarians, and the survival probability of becoming centenarians.

In the meantime, we have examined whether these factors have the same impact on both females and males [34]. The SPBC (70) of females and males, an indicator for assessing the production of centenarians, reflects the overall economic development level, mobile telephone subscribers, health expenditure, and sanitation facilities level in 32 countries. However, females have more to do with the power of explanation of these factors, than do males (Table 5; Males, $\mathrm{R}^{2}=0.303$; Females, $\left.\mathrm{R}^{2}=0.439\right)$ ).

Meanwhile, although the data quality of HMD is better compared to the UN data, the HMD data are not free from biases. For example, age exaggeration at very old ages in the U.S.A., as well as in some other countries, is not 
uncommon [35]. One of the simplest ways to check this is to compare the percentage distribution from age 95 to age 105 (see Additional file 2, Additional file 3). If a distribution is not in line with those of Sweden or Japan, the data quality of centenarians is likely poor [36]. The results of the data quality assessment of centenarians might have possible biases of such data.

The limitations regarding the accuracy of development variables are insufficient information for some countries over the past thirty years from 1980 to 2010. However, this study has used the mean rate of change index (MRCI), by considering the time and outcome, such as considering the growth rate, or rate of decline, in order to measure the change of socioeconomic indicators during the past thirty years.

Hence, the hypothesis states that the associations between SPBC (70) and socioeconomic factors (GNI, PEHGDP FMTS, ISF) could predict the healthy aging and production of centenarians. Hence, these factors could be explained by the survival probability of becoming centenarians that affects the healthy living of centenarians. For the proposed Models 1, 2, and 3 of females and males, if countries were to have higher GNI and PEHGDP, and higher FMTS and ISF factors, these factors would surely have an impact on the increase of SPBC (70) in all 32 countries.

\section{Conclusion}

The socioeconomic level in all 32 countries appears to have an important latent effect on the production of centenarians in both females and males. This study has identified the following four important aspects of socioeconomic indicators in the survival probability of becoming a centenarian for those aged 70: higher overall economic development level, public expenditure on health of GDP, mobile telephone subscribers as the standard of living, and the use of improved sanitation facilities for healthy aging. Thus, the socioeconomic level seems to affect an important on the survival probability of becoming a centenarian.

\section{Additional files}

Additional file 1: A list as the data assessment of SPBC (70) for study 32 countries.

Additional file 2: The number of distribution age 95 to 105 for selected countries in 2010.

Additional file 3: A percentage distribution age 95 to 105 for selected countries in 2010.

\section{Competing interests}

The authors declare that they have no competing interests.

\section{Authors' contributions}

JIK conceived the study, data analysis, statistical analysis, and drafted the manuscript. JIK made a substantial contribution to the analysis and interpretation of the data, and to the final writing of the paper. GBK contributed to the collection and arrangement of the data. Both authors read and approved the final manuscript.

\section{Acknowledgements}

We appreciate the reviewers for comments that have improved the manuscript.

This paper was sponsored by Wonkwang University in 2013.

\section{Author details}

${ }^{1}$ Division of Health and Welfare, Wonkwang University, Iksan 570-749, Republic of Korea. ${ }^{2}$ Management with International Business, Royal Holloway, University of London, Egham, Surrey TW20 OEX, UK.

Received: 5 January 2014 Accepted: 2 October 2014

Published: 21 October 2014

\section{References}

1. Kannisto $\mathrm{V}$ : On the survival of centenarians and the Span of life. Popul Stud J Demography 1988, 42(3):389-406.

2. Byass P: Towards a global agenda on ageing. Global Health Action 2008, 1. doi:10.3402/gha.v1i0.1908.

3. Berr C1, Balard F, Blain H, Robine JM: How to define old age: successful aging and/or longevity. Med Sci 2012, 28(3):281-287.

4. Robine J-M, Paccaud F: Nonagenarians and centenarians in Switzerland, 1860-2001: a demographic analysis. J Epidemiol Community Health 2005, 59:31-37.

5. Sachuk NN: Population longevity study: sources and indices. J Gerontol 1970, 25(3):262-264.

6. Kim Jl: Association between social factors of health ageing and longevity: determinants of the longevity index (LI) in OECD countries. Ageing Int 2014, 39(2):97-105.

7. Gavrilov LA, Gavrilova NS: Demographic consequences of defeating aging Rejuvenation Res 2010, 13(2-3):329-334. PMCID: PMC3192186.

8. Magnolfi SU, Petruzzi E, Pinzani P, Malentacchi F, Pazzagli M, Antonini FM: Longevity index (LI\%) and centenarity index (Cl\%): new indicators to evaluate the characteristics of aging process in the Italian population. Arch Gerontol Geriatr 2007, 44(3):271-276.

9. Kim Jl: Social factors associated with centenarian rate (CR) in 32 OECD countries. BMC Int Health Human Rights 2013, 13:16. doi:10.1186/1472-698X13-16.

10. Candore G, Balistreri CR, Listi F, Grimaldi MP, Vasto S, Colonna-Romano G, Franceschi C, Lio D, Caselli G, Caruso C: Immunogenetics, gender, and longevity. Ann N Y Acad Sci 2006, 1089:516-537.

11. Cairncross S, Hunt C, Boisson S, Bostoen K, Curtis V, Fung IC, Schmidt WP: Water, sanitation and hygiene for the prevention of diarrhoea. Int J Epidemiol 2010, 39(Suppl 1):i193-i205.

12. Lin HJ, Sung $\mathrm{TI}$, Chen $\mathrm{CY}$, Guo HR: Arsenic levels in drinking water and mortality of liver cancer in Taiwan. J Hazard Mater 2013, 262:1132-1138.

13. Kaplan WA: Can the ubiquitous power of mobile phones be used to improve health outcomes in developing countries? Global Health 2006, $2: 9$

14. McBride CM, Rimer BK: Using the telephone to improve health behavior and health service delivery. Patient Educ Couns 1999, 37(1):3-18.

15. Theou O, Brothers TD, Rockwood MR, Haardt D, Mitnitski A, Rockwood K: Exploring the relationship between national economic indicators and relative fitness and frailty in middle-aged and older Europeans. Age Ageing 2013, 42(5):614-619.

16. Rosero-Bixby L: The exceptionally high life expectancy of Costa Rican nonagenarians. Demography 2008, 45(3):673-691.

17. University of California, Berkeley (USA), and Max Planck Institute for Demographic Research (Germany). In Human Mortality Database. Available at www.mortality.org, accessed on June 02, 2014.

18. Mossakowska M, Barcikowska M, Broczek K, Grodzicki T, Klich-Raczka A Kupisz-Urbanska M, Podsiadly-Marczykowska T, Sikora E, Szybinska A, Wieczorowska-Tobis K, Zyczkowska J, Kuznicki J: Polish Centenarians Programme. Multidisciplinary studies of successful ageing: aims, methods, and preliminary results. Exp Gerontol 2008, 43(3):238-244.

19. Baker J, Meisner BA, Logan AJ, Kungl AM, Weir P: Physical activity and successful aging in Canadian older adults. J Aging Phys Act 2009, 17(2):223-235 
20. Rowe JW, Kahn RL: Human aging: usual and successful. Science 1987, 237(4811):143-149.

21. Hsu HC: Impact of morbidity and life events on successful aging. Asia Pac J Public Health 2011, 23(4):458-469.

22. Steyer A, Torkar KG, Gutiérrez-Aguirre I, Poljšak-Prijatelj M: High prevalence of enteric viruses in untreated individual drinking water sources and surface water in Slovenia. Int J Hyg Environ Health 2011, 214(5):392-398

23. Wright JA, Yang H, Rivett U, Gundry SW: Public perception of drinking water safety in South Africa 2002-2009: a repeated cross-sectional study. BMC Public Health 2012, 12(1):556.

24. Tumwebaze IK, Orach CG, Niwagaba C, Luthi C, Mosler HJ: Sanitation facilities in Kampala slums, Uganda: users' satisfaction and determinant factors. Int J Environ Health Res 2013, 23(3):191-204.

25. United Nations Development Programme (UNDP): Open Data. Available at https://data.undp.org, accessed on June 02, 2014.

26. United Nations (UN): UN Data, a World of Information, Dataset. Available at http://data.un.org, accessed on June 02, 2014.

27. Simmons BE: Average Rate of Change. In Mathwords: Terms and Formulas. http://www.mathwords.com, accessed on June 02, 2014.

28. Lenzen M: Decomposition analysis and the mean-rate-of-change index. Appl Energy 2006, 83(3):185-198.

29. Tarasevich I, Rydkina E, Raoult D: Outbreak of epidemic typhus in Russia. Lancet 1998, 352(9134):1151.

30. Ailshire JA, Crimmins EM: Psychosocial factors associated with longevity in the united states: age differences between the Old and oldest-Old in the health and retirement study. J Aging Res 2011, 2011:530534. PMCID: PMC3199053.

31. Wu JY1, Leung WY, Chang S, Lee B, Zee B, Tong PC, Chan JC: Effectiveness of telephone counselling by a pharmacist in reducing mortality in patients receiving polypharmacy: randomised controlled trial. BMJ 2006, 333(7567):522.

32. Wang F: Economic evaluations of the effects of longevity on telemedicine and conventional healthcare provision. Telemed J E Health 2011, 17(6):431-434.

33. Guthmann JP1, Bonnet M, Ahoua L, Dantoine F, Balkan S, van Herp M, Tamrat A, Legros D, Brown V, Checchi F: Death rates from malaria epidemics, Burundi and Ethiopia. Emerg Infect Dis 2007, 13(1):140-143.

34. Viña J, Borrás C, Gambini J, Sastre J, Pallardó FV: Why females live longer than males? Importance of the upregulation of longevity-associated genes by oestrogenic compounds. FEBS Lett 2005, 579(12):2541-2545.

35. Coale AJ, Kisker EE: Mortality crossovers: reality or Bad data? Popul Stud J Demography 1986, 40(3):389-401.

36. Zeng Y, Gu D: Reliability of age Reporting Among the Chinese Oldest-old in the CLHLS Datasets. In Healthy Longevity in China: Demographic Methods and Population Analysis. Edited by Zeng Y, Poston D, Vlosky DA, Gu D. The Netherlands: Springer; 2008:61-78.

\section{Submit your next manuscript to BioMed Central and take full advantage of:}

- Convenient online submission

- Thorough peer review

- No space constraints or color figure charges

- Immediate publication on acceptance

- Inclusion in PubMed, CAS, Scopus and Google Scholar

- Research which is freely available for redistribution 